Benefits Transfer and the Aquatic Environment: An Investigation into the Context of Fish Passage Improvement

\author{
Steven King \\ UNEP World Conservation Monitoring Centre
}

\author{
Iain Fraser* \\ University of Kent \\ and \\ La Trobe University \\ Jesse R. O’Hanley \\ University of Kent
}

September 2016

Published in Journal of Environmental Management

\author{
*Address for Correspondence: \\ Iain Fraser \\ School of Economics \\ Keynes College \\ University of Kent \\ Canterbury \\ Kent \\ CT2 7NP
}

Email: I.M.Fraser@kent.ac.uk 


\title{
Benefits Transfer and the Aquatic Environment: An Investigation into the Context of Fish Passage Improvement
}

\begin{abstract}
We present findings from a choice experiment investigating improvements in the aquatic environment from mitigation of barriers to fish passage. Implemented at a local and national level, results reveal positive preferences for increased numbers of fish species as well as fish abundance. In addition, we examine if in this case the willingness to pay estimates are suitable for direct transfer between national and local settings. For both samples, we consider the extent to which stated attribute nonattendance impacts estimates of willingness to pay and the potential ability of researchers to transfer values between contexts. Implications of the use of benefit transfer within this policy context are discussed in light of our findings.
\end{abstract}

Key Words: Fish Passage, Choice Experiment, Benefits Transfer, Stated Attribute Non-Attendance.

\section{Introduction}

River systems comprise some of the most complex, dynamic and bio-diverse ecosystems on earth (Dynesius and Nilsson, 1994). However, as a society, we have extensively modified these ecosystems in order to provide socioeconomic benefits such as water supply, flood suppression, power, and transportation. Obtaining these benefits typically involves the construction of river infrastructure (e.g. dams and road crossings), which fragments the continuity of rivers (Bednarek, 2001, Branco et al., 2014). Numerous studies have demonstrated the negative effects of these artificial in-stream structures on fish populations (e.g., Fullerton et al., 2010; Nislow et al., 2011). Removing physical barriers that inhibit fish passage has been demonstrated to deliver increased spawning (Burdick and Hightower, 2006), fish density (Gardner et al., 2013), diversity (Catalano et al., 2007), and rapid colonization of formerly impounded reaches (Roni et al., 2008). As such, there is now considerable interest in river barrier removal and mitigation as a cost effective means of improving fish populations at the catchment scale (Roni et al., 2008; Kemp and O'Hanley, 2010; O’Hanley, 2011; O’Hanley et al., 2013; King and O’Hanley, 2016).

River ecosystem improvements are typically driven by legislation. For example, across England and Wales, the Environment Agency (EA) has prioritised 2,500 river barriers for mitigation action in order to meet requirements of the EU Water Framework Directive (WFD) and eel regulations at an estimated cost of $£ 540$ million (Moghraby, 2008). However, 
such investment may not be justified on economic efficiency grounds, implying it could be put to better environmental protection use elsewhere. Indeed, where costs are disproportionate to benefits, derogations from the requirements of the WFD may be sought (Hanley et al, 2006b). As the benefits of river ecology improvements will frequently be positive externalities, non-market valuation techniques are required to inform cost benefit analysis (CBA) of river barrier mitigation action. Unfortunately, undertaking repeated valuation studies across catchments is both expensive and time consuming and, therefore, likely to be limited to large, controversial cases (Hanley et al., 2006b). Although benefit transfer (BT) can, in principle, provide an inexpensive solution to this problem (Morrison and Bennett, 2004), there remains considerable debate regarding its validity and which are the most appropriate methodologies of employing it (Hanley et al., 2006a).

In this paper, we estimate the willingness-to-pay (WTP) for local river ecosystem improvements delivered from river barrier mitigation actions using a choice experiment (CE). We administer the CE to local and national samples so that we can assess any differences that emerge and, in turn, inform future BT applications in this context. In particular, we evaluate if the national estimates for river ecosystem improvements for a generic river are valid for application in a specific local context. Furthermore, we explicitly examine the impact of attribute non-attendance (ANA) on our model estimates and BT robustness. To assess ANA, we explicitly asked all survey respondents to state which attributes they used in making their choices. The existence of ANA is potentially problematic for CE data analysis. If not taken into account during model estimation, WTP estimates may be biased.

We make three main contributions to the literature. First, we add to the small number of valuation studies on environmental improvements that result from modifications of multiple river barriers. To date, there are many studies that examine the benefits of improvements to general river quality, including those realised through the WFD, such as Hanley et al. (2006a,b), Bateman et al. (2011a), Bliem et al. (2012), and Glenk et al. (2015). However, few CE studies have focussed specifically on the ecosystem service benefits resulting from changes to river barriers that impact fish passage. Johnston et al. (2011) administered a CE to assess migratory fish passage restoration in the Pawtuxet watershed, Rhode Island, USA following the provision of fish passage facilities at 22 dams. They identify benefits from increased biological integrity, habitat accessibility, fish dependent wildlife, and viability of migratory fish runs. However, they did not find significant benefits from enhanced 
recreational fishing opportunities, unlike Laitila and Paulrud (2008), who considered river barrier removal in the Ljungan River in Sweden.

Our second contribution is to inform the debate surrounding the use of BT (Kaul et al., 2013). Specifically, we conduct a site specific CE and a generic national CE that were designed in such a way that we can compare attribute estimates of WTP between the samples. Within the literature, both significant differences (e.g., Morrison and Bennett, 2004) and no differences (e.g., Hanley et al., 2006b) in WTP estimates for CE attributes between samples have been observed. To assess differences in WTP, we employ the test introduced by Poe et al. (2005) that has been used extensively within the BT literature (e.g., Rolfe and Windle, 2012; Glenk et al., 2015).

Third and finally, as part of our CEs, we collected ANA information. In analysing our CE data, we assess the extent to which stated ANA impacts our WTP results for each CE. As observed by Glenk et al. (2015), much effort has gone into examining convergent validity (Kaul et al., 2013), whereas the emergence of transfer errors between sites might well occur because of differences in the way in which $\mathrm{CE}$ respondents have engaged with survey instrument (i.e., due to ANA). We consider the need to examine ANA an important issue when undertaking $\mathrm{CE}$ research and the lack of attention within the BT literature regarding this is a conspicuous oversight given its relative importance within the wider CE literature (e.g., Balcombe et al., 2011, 2015, Scarpa et al., 2013, Kragt, 2013 and Kehlbacher et al., 2013). Indeed, Scarpa et al. (2013) argue that ANA may be of greater importance than unobserved heterogeneity. To date, the only BT study that has considered ANA is Glenk et al. (2015). In that study, the authors examined ANA using an inferred approach that requires the estimation of an equality constrained latent class model specification. We take a different approach: we explicitly asked CE respondents to state which attributes they ignored. Although there is debate within the literature as to which approach is preferred, the use of stated ANA data is helpful within a BT context as it allows for straight forward comparisons of WTP without the need for being concerned about different model specifications. Thus, we consider the impact resulting from ANA on our BT results with the same model specification and so avoid the need to run different model specifications, which could yield differences in WTP over and beyond those that result from BT. 
In the present study, we explore BT issues by administering an almost identical CE to a national sample and a local sample for a specific river (i.e., the River Wey in South East England). We investigate preference heterogeneity for river ecology improvements delivered from barrier mitigation actions. In addition, we evaluate, in this limited context and points of comparison, the impact of such heterogeneity in the context of population effects that could compromise the validity of transferring national generic benefit estimates for river ecology improvements to our specific case study river, thus evaluating a novel form of BT.

The remainder of the paper is structured as follows. In Section 2, we introduce our case study river and discuss the design of our CE. In Section 3, we detail our choice model specifications. Results of our CE and our BT analysis are presented in Section 4. Finally, we discuss our findings and provide some concluding remarks in Section 5.

\section{The Choice Experiment}

We designed two almost identical CE survey instruments to examine preferences for improving the aquatic environment that result from the removal of physical in-stream barriers (e.g., dams, weirs, culverts, and locks) within a river system. The construction of our CE began with the development of a survey instrument for the River Wey. By drawing on river specific information, we were able to develop meaningful policy options. We then took the River Wey survey instrument and made minor changes to yield our National CE survey instrument. Specifically, the main difference in the design of the two CEs is that the local CE explicitly names a river: the River Wey. For the National survey we use identical information to describe the CE context and issues, but without explicitly naming a river. Thus, apart from the inclusion/exclusion of the river name, the two survey instruments were identical.

While it is acknowledged that the valuation context for the National survey will vary across respondents due to the proximity of a local river and any substitute rivers, the majority of households in the UK have a nearby watercourse that they can readily relate to as being their "local" river. Furthermore, river systems have been dramatically altered throughout the UK by the introduction of barriers, such that almost all rivers are subject to the environmental problem we consider in our CE. ${ }^{1}$

\footnotetext{
${ }^{1}$ A summary of the extent of river restoration activities in the UK demonstrates proximity of UK households to watercourses can be found at the River Restoration Centre web site: (http://www.therrc.co.uk/uk-projects-map.)
} 


\subsection{The River Wey}

The River Wey, located in South East England, is a tributary to the Thames with a watercourse of approximately 190 miles. Over the centuries, construction of dams, weirs, locks, and other hydro-modifications has significantly compromised river connectivity in the Wey such that fish and other aquatic organisms are unable to move freely through the system. The Environment Agency Fisheries Action Plan (EAFAP) for the catchment (EA, 2008) identifies the presence of physical obstructions as one of the key pressures on fish diversity and abundance. The EAFAP also notes that iconic species such as river otter and kingfisher are dependent on the existence of healthy fish populations.

\subsection{Survey Design}

\subsubsection{Attribute Selection}

Based on a literature review, extensive discussions with ecologists' familiar with the River $\mathrm{Wey}^{2}$ and UK rivers in general, focus group work, and piloting ${ }^{3}$ of the survey instrument, we arrived at four attributes:

(i) fish species diversity;

(ii) fish abundance;

(iii) provision of publically accessible river bank; and

(iv) amount of council tax.

A review of the literature reveals that attributes (i) and (ii) are two of the most important ecological responses to barrier mitigation for any river. These attributes can be linked to a range of ecosystem services and goods on which our economic analysis focuses (Bateman et al., 2011b). Importantly, our two ecological river quality attributes (i) and (ii) can also be linked to specific and quantifiable ecological outcomes. As such, they can be used to derive meaningful welfare estimates (Johnston et al., 2013) that can be used for BT. Figure 1 summarises the direct and indirect ecosystem services considered most relevant to increases in fish species richness and abundance and draws upon the UK National Ecosystem Assessment (UK NEA, 2011).

\footnotetext{
${ }^{2}$ The River Wey has been the subject of extensive ecological and environmental research activity: http://www.icer.soton.ac.uk/case-study-the-river-wey/

${ }^{3}$ Our two focus groups consisted of 10 individuals each from the South East of England. Their interpretation of the survey instrument was analysed using a combination of cognitive testing and verbal protocol analysis. Focus was on the River Wey survey instrument and how the information provided was perceived and understood. Following this pre-testing, a pilot survey was given to 82 adults from South East England. Results indicated good engagement and understanding of the tasks required.
} 
Figure 1: Improvements in river ecosystem services from river barrier mitigation actions

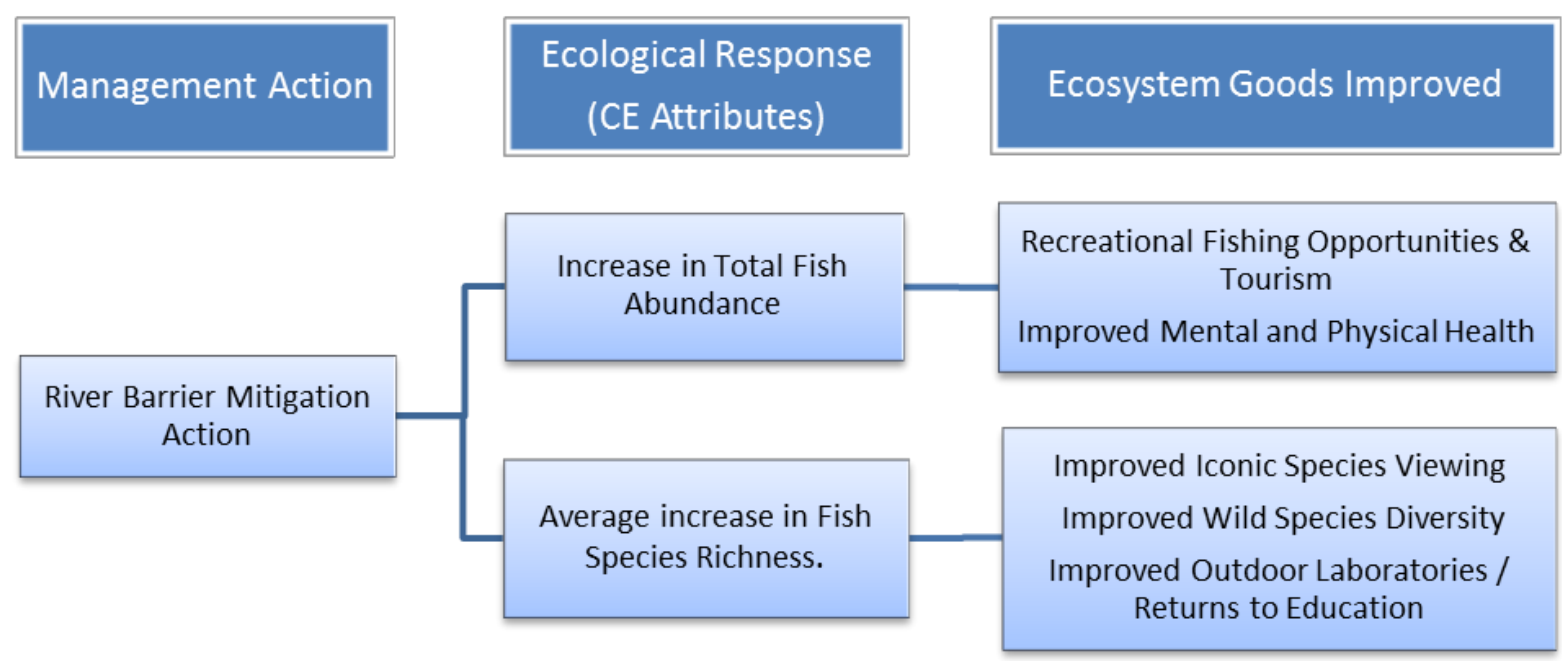

Figure 1 illustrates the explicit links between river management actions, such as barrier removal, and associated ecological responses that produce changes in ecosystem goods and services. We informed respondents of the ecosystem services that would improve as a result of increasing the levels of these ecological attributes in the background information of the CE. ${ }^{4}$ Specifically, fish species richness is explicitly linked to the diversity of wild species, iconic species viewing, and educational ecosystem goods, whereas the fish abundance attribute is explicitly linked to local community tourism and direct/community recreational ecosystem goods and associated health benefits.

Attribute (iii), public access to the river bank, was used to reduce informational or focusing biases on the ecological attributes, as suggested by Rolfe et al. (2002) and Hanley et al. (2010). Finally, given the nature of the study, a locally administered payment vehicle was chosen, namely a council tax increase (iv) to be collected annually for a period of five years. The duration of the payment vehicle follows MacDonald et al. (2011), who suggest that a one off-payment scenario is unrealistic and conservative when benefits may accrue over many years. $^{5}$

\footnotetext{
${ }^{4} \mathrm{~A}$ full version of the survey instrument is available on request.

${ }^{5}$ The set of attributes considered is far from exhaustive. To ensure that respondents only considered the attributes provided, we explicitly stated that "None of the options presented will increase flood risk, affect boating, or increase undesirable / non-native animals or plants in the river system."
} 


\subsubsection{Choice Card Design}

Given the chosen set of attributes, we next designed the choice cards. It was decided after the focus and pilot group work that each respondent (on behalf of his/her household) be asked to choose between three options comprising two river improvement options (A and B) that would provide an increase in at least one of the attributes for a given cost and a status quo option (Option C) of no attribute improvement and zero cost.

To place the choice task in context, the choice confronting each respondent was framed as follows: ${ }^{6}$

"As a society we can choose to spend more money on river improvements or not. We can also target how the money is spent. This survey is designed to understand how much residents would like to be spent on their local river systems and which characteristics of the system it should be spent on.

In the following sections, I will ask you to choose between two different improvement programmes (Options A or B) that can be provided at different costs to your household and a 'do nothing' approach (Option C) that will cost your household nothing by completing a series of choice cards. The levels and improvements offered in the choice card are based on a typical UK case study river that represents rivers across the UK generally."

The final set of attribute levels used in the CE, are presented in Table 1.

Table 1: Attributes and Levels

\begin{tabular}{llll}
\hline Attribute & Name & Units & Levels \\
\hline Fish species richness within 120m stretch & Variety & Number & $6,8,10$ and 12 \\
Total number of fish within 120m stretch & Fish & Number & $90,120,150$ and 180 \\
Miles of waterway foot path & Access & Miles & $34,44,54$ and 64 \\
Local tax payment per year for 5 years & Cost & $£$ & $0,5,15,30$ and 50 \\
\hline
\end{tabular}

From Table 1 we see that fish species richness attribute (Variety) is presented as a range of observed fish species within a 120 meter stretch of river. The range for the total number of fish attribute (Fish) is presented for the same stretch of river. Environment Agency (2008) survey data provided the values used for the levels for both of the ecological attributes. The access attribute (Access) was derived with reference to the number of existing miles of

\footnotetext{
${ }^{6}$ Only the last sentence in this framing text altered between the National and River Wey survey instruments.
} 
waterway towpaths and the additional miles that could be provided instead of funding barrier mitigation. Finally, the local tax attribute (Cost) was capped at the per capita cost among local residents of mitigating all known barriers in the River Wey.

For each choice card we provided two new management options and a status quo. The status quo option employed attribute levels based on findings of fish surveys completed by the Environment Agency (pers. comm.) in the River Wey. An example of the choice card presented to respondents is provided in Figure 2.

Figure 2: Example choice card

\begin{tabular}{|c|c|c|c|}
\hline Choice Card 1 & Option A & Option B & $\begin{array}{c}\text { Option C } \\
\text { (No Improvement) }\end{array}$ \\
\hline $\begin{array}{l}\text { Variety of River } \\
\text { Wildlife } \\
\text { (No. Fish Species } \\
\text { per } 120 \mathrm{~m})\end{array}$ & $x^{2} 10$ & $\log ^{8}$ & सु 6 \\
\hline $\begin{array}{c}\text { Publically } \\
\text { Accessible River } \\
\text { Bank (miles) }\end{array}$ & 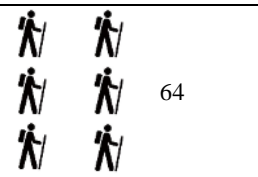 & iv ${ }^{4}$ & i \\
\hline $\begin{array}{c}\text { Total No. Fish } \\
\text { per } 120 \mathrm{~m} \text { of river }\end{array}$ & - 120 & 150 & +90 \\
\hline $\begin{array}{l}\text { One-off Increase } \\
\text { in Council Tax } \\
\text { (paid for } 5 \text { years } \\
\text { only) }\end{array}$ & $£ 10$ & $£ 30$ & None \\
\hline \multicolumn{4}{|c|}{ Please tick the one option that you most prefer: } \\
\hline & Option A & Option B & Option C \\
\hline
\end{tabular}

A main effects factorial design was generated for the CE. Priors recovered from the pilot survey were used to inform the final design, which was generated by minimising the associated $\mathrm{D}_{\mathrm{p}}$-error assuming a multinomial logit utility specification. The final design comprised 24 different choice sets. We separated these into four blocks of six different choice sets meaning that each respondent answered six choices so as to reduce respondent fatigue during the choice task. Reminders to consider budget constraints and substitute goods and/or services and rivers when making choices were included. 


\subsubsection{CE Implementation and Descriptive Statistics}

The surveys were administered to a panel of online respondents recruited by a market research company. Each respondent received a small financial payment for completing the entire CE. We rejected respondents who failed to meet screening criteria as well as responses that passed screening but failed to engage with the survey in a meaningful way (i.e., respondents that sped through the survey questions).

The National survey was administered so as to ensure a nationally representative sample based on region, gender, and age. The River Wey survey was administered to postcodes local to the River Wey catchment. With regard to the local sample we attempted as far as possible to recruit a sample reflecting local socioeconomic characteristics subject to the online panel coverage of the specific area.

In total we obtained 239 completed surveys for the nationally administered survey and 216 for the locally administered River Wey survey. From these we rejected respondents who indicated they objected to the council tax payment vehicle or did not believe the improvements offered were possible. This resulted in 222 useable survey responses $(1,322$ choice observations) for the national survey and 208 useable responses (1,236 choice observations) for the River Wey CE. In addition to the choice task, respondents were asked questions on their use of their local river, their socioeconomic characteristics, and protest motivations.

Finally, respondents were also asked to complete the Dunlap et al. (2000) 'New Environmental Paradigm' (NEP) index to capture psychometric measures of environmental attitudes. The appeal of the NEP is that it assesses general beliefs about the relationship between environment and society. The NEP index yielded a summary measure of environmental attitudes through the use of principle components analysis. ${ }^{7}$

A summary of these data as well as Student's t-test results to establish if the mean values for these variables were statistically different between samples are presented in Table 2.

\section{Table 2: Summary statistics for socioeconomic and river use variables}

\footnotetext{
${ }^{7}$ Using a variable such as NEP is often considered to introduce endogeneity into CE model specification. A discussion of this issue and why it might be overstated is provided in Balcombe et al. (2016).
} 


\begin{tabular}{|c|c|c|c|c|c|c|c|}
\hline \multirow{3}{*}{ Variable } & \multirow{3}{*}{ Units } & \multirow{3}{*}{ Units } & \multicolumn{2}{|c|}{ River Wey } & \multicolumn{2}{|c|}{ National } & \multirow{3}{*}{$\begin{array}{l}\text { Mean } \\
\text { Difference } \\
\text { p-Value }\end{array}$} \\
\hline & & & \multicolumn{2}{|c|}{$(\mathrm{N}=\mathbf{2 0 8})$} & \multicolumn{2}{|c|}{$(\mathrm{N}=222)$} & \\
\hline & & & Mean & Std Dev & Mean & Std Dev & \\
\hline Age & Years & $\begin{array}{l}1=16-25, \quad 2=26-35, \\
3=36-45, \quad 4=46-55, \\
5=56-65, \quad 6=66-75, \\
7=>76\end{array}$ & 3.56 & 1.409 & 3.653 & 1.738 & 0.546 \\
\hline Gender & Binary & Male $=0$, Female $=1$ & 0.625 & 0.485 & 0.54 & 0.499 & $0.076^{*}$ \\
\hline Income & $£ ’ 000 \mathrm{~s}$ & $\begin{array}{l}1=\text { less } \quad \text { than } 20, \\
2=20-39, \quad 3=40-59, \\
4=6-79, \quad 5=80-99, \\
6=100-120, \quad 7=\text { over } \\
120\end{array}$ & 2.476 & 1.322 & 2.032 & 1.074 & $0.000 * * *$ \\
\hline Education & Level & $\begin{array}{l}\text { 1=Primary, } \\
2=\text { Secondary, } 3=\mathrm{A} \\
\text { level, } 4=\text { Degree, } \\
5=\text { Post Grad }\end{array}$ & 3.23 & 1.069 & 3.067 & 1.018 & 0.11 \\
\hline Visits & Level & $\begin{array}{l}1=\text { Once a day, } \\
2=\text { Once a week, } \\
3=\text { Once a month, } \\
4=2 \text { to } 6 \text { per year, } \\
5=\text { Once a year, } \\
6=\text { Never. }\end{array}$ & 3.918 & 1.509 & 3.657 & 1.452 & $0.070^{*}$ \\
\hline NEP & $\begin{array}{l}\text { Composite } \\
\text { index }\end{array}$ & & 0.031 & 0.975 & 0.022 & 1.004 & 0.466 \\
\hline
\end{tabular}

Note: Statistically significant at $* * * 1 \%, * * 5 \%$. and $* 10 \%$ levels.

Table 2 reveals respondents in the National sample are different in several dimensions, on average, to those from the River Wey sample. For example, they are more likely to be male (than Wey respondents), have lower incomes, and visit their local river less regularly than those in the River Wey sample. Thus, there are clearly some differences in sample composition. In the analysis that follows we have not modified our samples to compensate for these differences. Instead, we include these variables in our analysis to control for their effect on model results and WTP estimates. 


\section{Econometric Analysis}

The CE methodology is based upon Lancaster's characteristics theory of goods, with the associated choice models underpinned by random utility theory. The random utility model is specified in two parts: an observable deterministic component and an unobservable random component (Hensher et al., 2005). We assume a respondent $i$ makes one choice from a finite set. The utility function of respondent $i$ based on selecting an alternative $j$ from choice set $t$ is:

$U_{i j t}=\beta_{i} \boldsymbol{x}_{i j t}+\varepsilon_{i j t}$

where $U_{i j t}$ is the utility obtained by respondent $i$ from choosing option $j$ in choice set $t, \boldsymbol{\beta}_{i}$ is a vector of parameters to be estimated, and $\boldsymbol{x}_{i j t}$ is a vector of $k$ attributes. In keeping with standard practice, $\varepsilon_{i j t}$ is the unobservable random component from the researcher's perspective, which is assumed to be type-1 extreme value distributed (Train, 2003). If we assume that all respondents maximise utility, then alternative $j$ will be selected over all others if it has the largest utility.

To allow for preference heterogeneity, it is now common for researchers to employ a random parameters logit (RPL) specification that considers the panel structure of the data (Train, 2003). The RPL allows for parameter estimates $\boldsymbol{\beta}_{i}$ in the utility function to vary across individuals so that individual preference heterogeneity can be captured. The variation in $\boldsymbol{\beta}_{i}$ is generated for a given respondent $i$ by the addition of a vector of deviation parameters $\boldsymbol{\eta}_{i}$.

$\boldsymbol{\beta}_{i}=\overline{\boldsymbol{\beta}}+\boldsymbol{\eta}_{i}$

where $\overline{\boldsymbol{\beta}}$ is the vector of sample means and $\boldsymbol{\eta}_{i}$ is a vector of error terms randomly drawn from distributions specified by the analyst with an associated covariance matrix $\boldsymbol{\Omega}_{i}$. As the mixed logit model specification has no closed form, it is approximated through simulation by repeatedly drawing values of $\boldsymbol{\beta}_{i}$ from pre-specified distributions. Parameter estimates are then obtained by maximising the simulated likelihood function across the entire sample of respondents (Train, 2003). 


\subsection{Model Specifications}

Our preferred model specification begins with the observed component of utility $\left(v_{i j t}=\right.$ $\left.\boldsymbol{\beta}_{i}^{\prime} \boldsymbol{x}_{i j t}\right)$ :

$v_{i j t}=\beta_{1 i} \times A S C_{i j t}+\beta_{2 i} \times$ Variety $_{i j t}+\beta_{3 i} \times$ Access $_{i j t}+\beta_{4 i} \times$ Fish $_{i j t}+\beta_{5 i} \times$ Cost $_{i j t}(3)$

where ASC is the alternative specific constant that takes the value 1 if the status quo (Option C) is selected, Variety is the number of fish species in a $120 \mathrm{~m}$ stretch of river, Access is the miles of publically accessible river bank, Fish is the total number of fish in a 120m stretch of river, and Cost is the amount spent on river barrier mitigation action. In terms of random parameters, we specify a normal distribution for Variety, Access, and Fish. In keeping with many other papers in the literature (e.g., Rolfe and Windle, 2012) we assume that Cost is a fixed parameter.

It is also common within the BT literature to employ various methods to control for differences in sample composition and other issues that can bias results (Johnston and Duke, 2010; Johnston and Rosenberger, 2010; Östberg et al., 2013). We control for differences in our sample populations by including socioeconomic and river use data in our model specifications. In this study, we include the socio-economic and attitudinal variables described in Table 2 in the status quo utility function: Age, Gender, Income, Education, Visit, and NEP.

In addition, given the design and purpose of our $\mathrm{CE}$ it is potentially important that we consider possible heterogeneity of interpretation of the status quo situation by our National sample respondents. Specifically, we need to understand if the status quo option in our CE has been perceived in the same way across different regions that we have drawn from in generating our national sample. This issue has previously been considered within CEs by several researchers (e.g., Rolfe and Windle, 2012; Mariel et al., 2013; Ahtiainen et al., 2015) using various methodological approaches. In this study, we have constructed dummy variables to examine if there are any systematic differences by region in relation to how the status quo option is perceived. Specifically, our National survey is drawn from 10 regions. In order to yield an econometrically reasonable number of regional dummies we aggregated the 10 regions into three groups based on annual average rainfall levels capturing differences in regional location and typography which in turn captures potential differences in local rivers. 
The three aggregate regional dummies are labelled as Low (composed of regions London; South East and Eastern), Medium (composed of regions East Midlands, West Midlands and Yorkshire) and High (composed of regions South West, Wales, North West and North East). Finally, we have also generated a dummy variable to indicate the River Wey CE data when estimating a pooled model specification.

\subsection{ANA Data}

To generate our ANA model results, we used the ANA data collected from both CEs. The data were collected by asking the question shown in Figure 3.

\section{Figure 3: ANA question}

Question 3: Please indicate any of the characteristics you ignored when making ALL of your choices - please place an 'X' in all boxes that apply.

Variety of River Wildlife (No. Fish Species per 120m).

Publically Accessible River Bank (miles).

Total Number of Fish per $120 \mathrm{~m}$ of river.

One-off Increase in Council Tax (paid for 5 years only).

I did not ignore any of the characteristics.

The format of the question is standard within the literature and follows the most common approach to ANA by presenting the question to respondents after all CE cards have been completed. A summary of ANA results by attribute and CE context is provided in Table 3.

Table 3: ANA data summary

\begin{tabular}{lll}
\hline Attribute & $\begin{array}{l}\text { River Wey } \\
\text { Percentages }\end{array}$ & $\begin{array}{l}\text { National } \\
\text { Percentages }\end{array}$ \\
\hline Variety & 8.7 & 6.3 \\
Access & 9.1 & 9.5 \\
Total Fish & 10.1 & 9.0 \\
Cost & 9.6 & 4.1 \\
\hline
\end{tabular}

The main thing to note about Table 2 is that the extent of stated ANA is lower than reported in many other studies (e.g., Balcombe et al., 2011, 2015; Kehlbacher et al., 2013; Kragt, 
2013; Scarpa et al., 2013). There are also only small differences in percentage terms between the two survey contexts, suggesting that ANA will not be a serious issue in our current study.

In terms of model estimation, we followed the approach proposed by Hensher et al. (2005b) and used by various researchers, including Kehlbacher et al. (2013) and Kragt (2013). Specifically, we assumed that the marginal utility for a specific attribute is zero for a respondent who has indicated that a specific attribute has not been attended. Although, not the only way in which to employ stated ANA data within a model specification, it does allow us to examine the extent to which ANA might introduce yet another issue when it comes to BT implementation. ${ }^{8}$

\subsection{Poe et al. (2005) Test}

Based on the model results generated for the CEs for both full and ANA data, we estimated WTP for each attribute. To assess the similarity and potential of BT between local (River Wey) and national (nameless local river) settings combined with ANA information or not, we implemented the combinatorial test introduced by Poe et al. (2005). This is a statistical test of the difference between the mean for all WTP estimates for both CEs and data contexts. This is a non-parametric one tail test that is implemented by first generating a distribution of 1,000 WTP estimates using the method introduced by Krinsky and Robb (1986). ${ }^{9}$

\section{$4 \quad$ Model Results}

In this section, we present results for both CEs as well as a Pooled data model. Results were generated by making 500 simulated draws for each model specification using the NLOGIT version 5 software package (Greene, 2012). We first report model results, then WTP estimates. Finally, we examine differences between WTP estimates for the River Wey and National CEs using the test proposed by Poe et al. (2005).

\subsection{Model Results}

\subsubsection{Standard Data Context}

Table 4 presents model results for the River Wey, National, and Pooled model specifications.

\footnotetext{
${ }^{8}$ Within the stated ANA literature an alternative approach to using data is the shrinkage approach (e.g., Scarpa et al., 2013, and Kehlbacher et al., 2013). When comparing the various approaches that use stated ANA data, the significant gain from model fit comes from the use of the ANA data, whereas the benefits obtained from employing the shrinkage approach (as opposed to setting the marginal to zero) are far less significant. ${ }^{9}$ Morrison et al. (2002) present a number of alternative benefit transfer tests including one based on the estimation of compensating surplus that is also used by Glenk et al. (2015).
} 
Table 4: RPL Results

\begin{tabular}{|c|c|c|c|c|c|c|}
\hline \multirow[t]{2}{*}{ Model } & \multicolumn{2}{|c|}{ River Wey } & \multicolumn{2}{|c|}{ National } & \multicolumn{2}{|c|}{ Pooled } \\
\hline & Coef. & p-Value & Coef. & p-Value & Coef. & p-Value \\
\hline \multicolumn{7}{|c|}{ Random Parameters } \\
\hline ASC & $-3.296 * * *$ & 0.002 & $-3.925 * * *$ & 0.000 & $-3.321 * * *$ & 0.000 \\
\hline Variety & $0.216 * * *$ & 0.000 & $0.202 * * *$ & 0.000 & $0.208 * * *$ & 0.000 \\
\hline Access & $0.037 * * *$ & 0.000 & $0.042 * * *$ & 0.000 & $0.040 * * *$ & 0.000 \\
\hline Total Fish & $0.007 * * *$ & 0.000 & $0.013 * * *$ & 0.000 & $0.011 * * *$ & 0.000 \\
\hline \multicolumn{7}{|c|}{ Std. Dev. of Random Parameters } \\
\hline ASC & $2.62940 * * *$ & 0.000 & $2.579 * * *$ & 0.000 & $2.675^{* * *}$ & 0.000 \\
\hline Variety & $.20823 * * *$ & 0.000 & $0.122 * * *$ & 0.004 & $0.162 * * *$ & 0.000 \\
\hline Access & $.03066 * * *$ & 0.000 & $0.024 * * *$ & 0.007 & $0.028 * * *$ & 0.000 \\
\hline Total Fish & $.01377 * * *$ & 0.000 & $0.012 * * *$ & 0.000 & $0.013 * * *$ & 0.000 \\
\hline \multicolumn{7}{|c|}{ Non-Random Parameters in all Utility Functions } \\
\hline Cost & $-0.075 * * *$ & 0.006 & $-0.059 * * *$ & 0.000 & $-0.066 * * *$ & 0.000 \\
\hline \multicolumn{7}{|c|}{ Non-Random Parameters in the Status Quo Utility Function } \\
\hline NEP & -0.193 & 0.501 & $-0.519 * *$ & 0.049 & $-0.389 * *$ & 0.040 \\
\hline Educ & $0.503 *$ & 0.063 & $0.427 *$ & 0.091 & $0.538 * * *$ & 0.004 \\
\hline Income & $-0.569 * *$ & 0.020 & 0.299 & 0.209 & -0.236 & 0.152 \\
\hline Visit & 0.001 & 0.997 & $0.483 * * *$ & 0.006 & $0.233^{* *}$ & 0.043 \\
\hline Female & 0.562 & 0.327 & -0.219 & 0.656 & 0.027 & 0.942 \\
\hline Low & & & -0.620 & 0.325 & -0.366 & 0.542 \\
\hline High & & & 0.699 & 0.263 & 0.543 & 0.372 \\
\hline Wey & & & & & -0.658 & 0.217 \\
\hline \multicolumn{7}{|c|}{ Model Diagnostics } \\
\hline Log-Likelihood & -812.39 & & -911.85 & & -1738.77 & \\
\hline AIC & 1652.8 & & 1855.7 & & 3511.5 & \\
\hline Pseudo $\mathrm{R}^{2}$ & 0.407 & & 0.377 & & 0.387 & \\
\hline
\end{tabular}

Note: Statistically significant at $* * * 1 \%, * * 5 \%$, and $* 10 \%$ levels.

As can be seen in Table 4, the coefficients for all CE attributes across the different model specifications have their expected signs and are statistically significant. For example, the negative sign for Cost conforms to economic theory that rational respondents are less likely, ceteris paribus, to choose options with a higher cost. Furthermore, all the standard deviations for the random parameters are statistically significant. We can also see from Table 4 that the ASC is significant and negative for all model specifications, indicating a general preference to choose river improvement options. 
Turning to the socio-economic and river use parameters, we observe several interesting results. First, our dummy variables for region are not statistically significant which indicates that there would appear to be no difference in how the National sample respondents perceived the status quo option. Second, for the Pooled model, the dummy variable identifying River Wey survey respondents (Wey) is also statistically insignificant indicating that River Wey and National respondents are prepared to pay equal amounts for improvement options. Third, the remaining variables provide slightly more explanatory power for the National sample compared to the Wey River sample. Interestingly, income is significant and negative in the River Wey sample whereas NEP is significant and negative for the National sample.

\subsubsection{ANA Data Context}

Table 5 presents model results for the River Wey, National, and Pooled model specifications with ANA response data included.

Table 5: ANA Data RPL Results

\begin{tabular}{|c|c|c|c|c|c|c|}
\hline \multirow[t]{2}{*}{ Model } & \multicolumn{2}{|c|}{ River Wey } & \multicolumn{2}{|c|}{ National } & \multicolumn{2}{|c|}{ Pooled } \\
\hline & Coef. & p-Value & Coef. & p-Value & Coef. & p-Value \\
\hline \multicolumn{7}{|c|}{ Random Parameters } \\
\hline ASC & $-3.551 * * *$ & 0.002 & $-4.136^{* * *}$ & 0.000 & $-3.501 * * *$ & 0.000 \\
\hline Variety & $0.222 * * *$ & 0.000 & $0.186 * * *$ & 0.000 & $0.202 * * *$ & 0.000 \\
\hline Access & $0.039 * * *$ & 0.000 & $0.042 * * *$ & 0.000 & $0.041 * * *$ & 0.000 \\
\hline Total Fish & $0.008 * * *$ & 0.000 & $0.012 * * *$ & 0.000 & $0.011 * * *$ & 0.000 \\
\hline \multicolumn{7}{|c|}{ Std. Dev. of Random Parameters } \\
\hline ASC & $2.869 * * *$ & 0.000 & $2.653 * * *$ & 0.000 & $2.806 * * *$ & 0.000 \\
\hline Variety & $0.229 * * *$ & 0.000 & $0.105 * *$ & 0.013 & $0.162 * * *$ & 0.000 \\
\hline Access & $0.020^{*}$ & 0.059 & $0.019 *$ & 0.058 & $0.019 * * *$ & 0.006 \\
\hline Total Fish & $0.015 * * *$ & 0.000 & $0.011 * * *$ & 0.000 & $0.013 * * *$ & 0.000 \\
\hline \multicolumn{7}{|c|}{ Non-Random Parameters in all Utility Functions } \\
\hline Cost & $-0.076 * * *$ & 0.000 & $-0.056 * * *$ & 0.000 & $-0.064 * * *$ & 0.000 \\
\hline \multicolumn{7}{|c|}{ Non-Random Parameters in the Status Quo Utility Function } \\
\hline NEP & -0.234 & 0.425 & $-0.514 * *$ & 0.044 & $-0.416 * *$ & 0.038 \\
\hline Edu & $0.523 *$ & 0.068 & 0.401 & 0.111 & $0.505 * * *$ & 0.009 \\
\hline Income & $-0.627 * *$ & 0.012 & 0.239 & 0.312 & $-0.281 *$ & 0.095 \\
\hline Visit & 0.018 & 0.917 & $0.533 * * *$ & 0.002 & $0.240 * *$ & 0.036 \\
\hline Female & 0.708 & 0.249 & -0.239 & 0.620 & 0.034 & 0.928 \\
\hline Low & & & -0.589 & 0.341 & 0.729 & 0.269 \\
\hline High & & & 0.711 & 0.242 & -0.303 & 0.643 \\
\hline Wey & & & & & -0.455 & 0.445 \\
\hline \multicolumn{7}{|c|}{ Model Diagnostics } \\
\hline Log-Likelihood & -817.49 & & -928.80 & & -1762.62 & \\
\hline AIC & 1663.0 & & 1889.6 & & 3559.2 & \\
\hline
\end{tabular}


Note: Statistically significant at $* * * 1 \%, * * 5 \%$, and $* 10 \%$ levels.

The first thing to note about Table 5 is that the results are not qualitatively different to those reported in Table 4. Once again all of the CE attributes are statistically significant. In addition, the standard deviations for the random parameters are also all significant. We also see a very similar pattern of results for the socio-economic data, the river use measure and the various regional dummies. Thus, an initial consideration of the model results suggests that differences appear to be modest when taking account of ANA data at least in this context. ${ }^{10}$

\subsection{WTP Estimates and Poe Test}

In Table 6 we report WTP estimates for the full data and ANA data model specifications. The Krinsky and Robb (1986) method with 5,000 draws was used to establish statistical significance and $95 \%$ confidence intervals for the WTP estimates for each attribute.

Table 6: WTP Estimates

\begin{tabular}{|c|c|c|c|}
\hline Full Data & WTP (£) & p-Value & $\begin{array}{l}\text { 95\% Confidence } \\
\text { Interval }\end{array}$ \\
\hline River Wey Variety & $2.882 * * *$ & 0.000 & $2.174-3.589$ \\
\hline River Wey Access & $0.494 * * *$ & 0.000 & $0.349-0.638$ \\
\hline River Wey Fish & $0.099 * * *$ & 0.000 & $0.053-0.145$ \\
\hline National Variety & $3.414 * * *$ & 0.000 & $2.632-4.196$ \\
\hline National Access & $0.717 * * *$ & 0.000 & $0.546-0.887$ \\
\hline National Fish & $0.222 * * *$ & 0.000 & $0.170-0.275$ \\
\hline Pooled Variety & $3.134 * * *$ & 0.000 & $2.610-3.657$ \\
\hline Pooled Access & $0.609 * * *$ & 0.000 & $0.497-0.721$ \\
\hline Pooled Fish & $0.159 * * *$ & 0.000 & $0.123-0.194$ \\
\hline ANA Data & WTP (f) & p-Value & $\begin{array}{l}95 \% \text { Confidence } \\
\text { Interval }\end{array}$ \\
\hline River Wey Variety & $2.912 * * *$ & 0.000 & $2.169-3.654$ \\
\hline River Wey Access & $0.513 * * *$ & 0.000 & $0.370-0.655$ \\
\hline River Wey Fish & $0.109 * * *$ & 0.000 & $0.060-0.158$ \\
\hline National Variety & $3.323 * * *$ & 0.000 & $2.524-4.122$ \\
\hline National Access & $0.741 * * *$ & 0.000 & $0.568-0.915$ \\
\hline National Fish & $0.221 * * *$ & 0.000 & $0.166-0.276$ \\
\hline Pooled Variety & $3.148 * * *$ & 0.000 & $2.603-3.692$ \\
\hline Pooled Access & $0.636 * * *$ & 0.000 & $0.523-0.748$ \\
\hline Pooled Fish & $0.164 * * *$ & 0.000 & $0.126-0.201$ \\
\hline
\end{tabular}

Note: Statistically significant at $* * * 1 \%, * * 5 \%$, and $* 10 \%$ levels.

\footnotetext{
${ }^{10} \mathrm{We}$ also note that the inclusion of the ANA data does not improve model diagnostic measures as is commonly the case reported in the literature. As Balcombe et al. (2011) explain the inclusion of ANA data by setting marginal utility to zero need not result in improved model performance.
} 
Taking the three attributes in turn, we observe that the point estimates and confidence intervals for all the model specification are of similar magnitudes. Importantly, there are no sign reversals and all the signs are as expected. The Pooled data specification yields WTP estimates that are between the estimates for the River Wey and National CEs.

When comparing the full data and ANA data specifications, we see that for the River Wey, all of the WTP estimates increase but this is not the case for the National CE. Thus, a simple examination of the results would suggest that the two sets of WTP estimates have converged to a certain extent once we take account of the ANA data. Indeed, a simple examination of the confidence intervals suggests that the degree of overlap for the reported confidence intervals is significantly greater for the ANA data specifications compared to the full data specifications. However, whilst overlapping confidence intervals are useful in providing initial insight into how suitable the generic national WTP estimates might be for BT to other rivers, further analysis is required in order to estimate the expected magnitude of error associated with this practice. For our application, we are interested in determining if the differences in mean WTP estimates are statistically significant. From a policy perspective, we are particularly interested in investigating if the nationally derived WTP estimates can be transferred to other catchments for which there is currently no data. To test this, we have implemented the Poe et al. (2005) test with results reported in Table 7.

Table 7: Poe et al. (2005) Test Results

\begin{tabular}{lll}
\hline Hypothesis & Attribute & p-Value \\
\hline $\mathrm{H}_{0}: \mathrm{WTP}_{\mathrm{Wey}}-\mathrm{WTP}_{\text {Nat }}=0$ & Variety & 0.157 \\
$\mathrm{H}_{1}: \mathrm{WTP}_{\mathrm{Wey}}-\mathrm{WTP}_{\text {Nat }}<0$ & Access & $0.025^{* *}$ \\
& Fish & $0.001^{* * *}$ \\
\hline $\mathrm{H}_{0}: \mathrm{WTP}_{\mathrm{Wey}}-\mathrm{WTP}_{\text {ANAWey }}=0$ & Variety & 0.475 \\
$\mathrm{H}_{1}: \mathrm{WTP}_{\mathrm{Wey}}-\mathrm{WTP}_{\text {ANAWey }}<0$ & Access & 0.426 \\
& Fish & 0.379 \\
\hline $\mathrm{H}_{0}: \mathrm{WTP}_{\mathrm{Wey}}-\mathrm{WTP}_{\text {ANANat }}=0$ & Variety & 0.197 \\
$\mathrm{H}_{1}: \mathrm{WTP}_{\text {Wey }}-\mathrm{WTP}_{\text {ANANat }}<0$ & Access & $0.016^{* *}$ \\
& Fish & $0.000^{* * *}$ \\
\hline $\mathrm{H}_{0}: \mathrm{WTP}_{\text {Nat }}-\mathrm{WTP}_{\text {ANAWey }}=0$ & Variety & 0.180 \\
$\mathrm{H}_{1}: \mathrm{WTP}_{\text {Nat }}-\mathrm{WTP}_{\text {ANAWey }}<0$ & Access & $0.040^{* *}$ \\
& Fish & $0.001^{* * *}$ \\
\hline $\mathrm{H}_{0}: \mathrm{WTP}_{\text {Nat }}-\mathrm{WTP}_{\text {ANANat }}=0$ & Variety & 0.450 \\
$\mathrm{H}_{1}: \mathrm{WTP}_{\text {Nat }}-\mathrm{WTP}_{\text {ANANat }}<0$ & Access & 0.425 \\
& Fish & 0.490 \\
\hline $\mathrm{H}_{0}: \mathrm{WTP}_{\text {ANAWey }}-\mathrm{WTP}_{\text {ANANat }}=0$ & Variety & 0.221 \\
$\mathrm{H}_{1}: \mathrm{WTP}_{\text {ANAWey }}-\mathrm{WTP}_{\text {ANANat }}<0$ & Access & $0.026^{* *}$ \\
& Fish & $0.001^{* * *}$ \\
\hline
\end{tabular}


Note: Statistically significant at $* * * 1 \%, * * 5 \%$, and $* 10 \%$ levels.

The first thing to note about Table 7 is that we do not reject the null hypothesis when we compare full data against ANA data for both samples. Thus, in this specific study it would appear that the impact of ANA on model results is minimal. This result is maybe not that surprising given the relatively low level of ANA identified in the data.

Turning to the tests that compare the National and River Wey results for all data specifications, we find statistically significant differences for WTP for Access and Fish and these results remain when we take the ANA data into account. However, we do not find a statistical difference for Variety. Thus, we would be able to transfer values for Variety from the National to the local level but not for the other attributes.

\section{$5 \quad$ Discussion and Conclusions}

In this paper, we present the findings of CEs to estimate the benefits of ecological improvements delivered through river barrier mitigation. We administered the CEs to a national sample and a local sample involving a specific river (the River Wey in South East England). Analysis of the CE results shows respondents in both sample groups have preferences for increasing fish species richness, abundance and access to rivers. In addition, we find the ASC in the model specifications to be consistently statistically significant and negative across both sample groups, indicating respondents have a general preference for river improvement. Also, we have found that the use of stated ANA data did not change fundamentally affect our model results and differences in WTP between samples. Specifically, because the degree of ANA is not large compared to what is commonly reported in the literature, the changes that occur to our model results and the subsequent estimates of WTP are statistically insignificant.

In the context of river barrier mitigation, our results indicate that differences in WTP for total number of fish and miles of foot path are significantly different between respondents attending to these attributes in the River Wey and national sample groups. Accordingly, under the assumption that all beneficiaries are interested in improving these attributes at a proposed local river, the WTP estimated from the national sample with or without ANA data included would not suitable for transfer at least as far as this study is concerned. However, we do find the differences for WTP for increases in fish species richness is insignificant 
between the National and River Wey samples. This indicates that WTP estimates for fish species richness are robust to transfer from the National to local river context. This result is likely to be of interest to policy makers and river managers involved in cost benefit analysis of river restoration options.

Finally, how ANA is assessed remains an open research question. In this study, we have employed stated ANA data, since we explicitly asked respondents about attribute use. The alternative approach of inferred ANA also has merit, although it does require the use of a latent class model specification that means resulting estimates of WTP are derived from different model specifications. The obvious benefit of using stated ANA is that we can introduce the information in such a way that model performance under identical model specifications can be compared, be they mixed logit or latent class. However, we also acknowledge that the availability of stated ANA requires researchers to build this aspect of data collection into their survey instruments, which is rarely undertaken. Therefore, we advocate that researchers need to carefully consider the collection of this type of data, not only because of the potential implications for BT, but more generally for the points raised by Scarpa et al. (2013) and the various results reported by others in the literature.

\section{Acknowledgements}

The authors thank the insightful comments of both referees. We also acknowledge the supported provided in part by the UK Economic and Social Research Council (ESRC) via the South East Doctoral Training Centre (Grant No. ESJ500148/1), as well as Lynda Newbold and Paul Kemp of the University of Southampton for the provision of case study data and the Faculty of Social Sciences at the University of Kent for funding survey administration.

\section{References}

Ahtiainen, H., Pouta, E. and Artell, J. (2015). Modelling asymmetric preferences for water quality in choice experiments with individual-specific status quo alternatives. Water Resources and Economics, 12: 1-39.

Balcombe, K., Burton, M. and Rigby, D. (2011). Skew and Attribute Non-Attendance within the Bayesian Mixed Logit Model, Journal of Environmental Economics and Management, 62: 446-461. 
Balcombe, K.G., Fraser, I.M. and McSorley, E. (2015). Attribute Non-Attendance and Choice Experiments: Using Eye-Tracking to Understand Respondent Behaviour, Journal of Applied Econometrics, 30(3): 447-467.

Balcombe,K.G., I.M. Fraser, Lowe, B. and Souza-Monteiro, D. (2016). Attribute NonAttendance and Attribute Importance Ranking Responses within Discrete Choice Experiments, American Journal of Agricultural Economics, 98(1): 54-73.

Bateman, I.J., Brouwer, R., Ferrini, S., Schaafsma, M., Barton, D.N., Dubgaard, A., Hasler, B., Hime, S., Liekens, I., Navrud, S., De Nocker, L., Sceponaviciut, R. and Semeniene, D. (2011a). Making Benefit Transfers Work: Deriving and Testing Principles for Value Transfers for Similar or Dissimilar Sites Using a Case Study the Non-Market Benefits of Water Quality Improvements Across Europe, Environmental and Resource Economics, 50(3): 365-387.

Bateman, I., Mace, G., Fezzi, C., Atkinson, G. and Turner, K. (2011b). Economic analysis of ecosystem service assessments. Environmental Resource Economics, 48: 177-218.

Bednarek, A. T. (2001). Undamming rivers: a review of the ecological impacts of dam removal. Environmental Management, 27 (6): 803-814.

Bliem, M., Getzner, M. and Rodiga-Laßnig, P. (2012). Temporal Stability of Individual Preferences for River Restoration in Austria Using a Choice Experiment, Journal of Environmental Management, 103: 65-73.

Catalano, M. J., Bozek, M. A. and Pellett, T. D. (2007). Effects of dam removal on fish assemblage structure and spatial distributions in the Baraboo River, Wisconsin. North American Journal of Fisheries Management, 27(2): 519-530.

Dynesius, M. and Nilsson, C. (1994). Fragmentation and flow regulation of river systems in the northern third of the world. Science, 266(5186): 753-762. 
Dunlap, R., Van Liere, K., Mertig, A. and Jones, R. (2000). Measuring endorsement of the New Ecological Paradigm: A revised NEP scale. Journal of Social Issues, 56(3): 425-442.

Environment Agency (EA) (2008). The Wey Valley fisheries action plan. Available online: http://lfcc.org.uk/downloads/category/16?download=31 <Accessed 8/12/2015>.

Fullerton, A., Burnett, K., Steel, E., Flitcroft, R., Pess, G., Feist, B., Torgersen, C., Miller, D. and Sanderson, B. (2010). Hydrological connectivity for riverine fish: Measurement challenges and research opportunities. Freshwater Biology, 55(11): 2215-2237.

Gardner, C., Coghlan, S., Zydlewski, J. and Saunders, R. (2013). Distribution and abundance of stream fishes in relation to barriers: implications for monitoring stream recovery after barrier removal. River Research and Applications, 29(1): 65-78.

Glenk, K., Martin-Ortega, J., Pulido-Velazquez, M. and Potts, J. (2015). Inferring Attribute Non-Attendance from Discrete Choice Experiments: Implications for Benefit Transfer, Environmental and Resource Economics, 60: 497-520.

Greene, W.H. (2012). NLOGIT Version 5. Reference Guide, Econometric Software Inc. Available online: www.nlogit.com <Accessed 8/12/2015>.

Hanley, N., Wright, R. and Alvarez-Farizo, B. (2006a). Estimating the economic value of improvements in river ecology using choice experiments: An application to the Water Framework Directive. Journal of Environmental Management, 78: 183-193.

Hanley, N., Colombo, S., Tinch, D., Black, A. and Aftab, A. (2006b). Estimating the benefits of water quality improvements under the Water Framework Directive: Are the benefits transferable? European Review of Agricultural Economics, 33(3): 391-413.

Hanley N., Czajkowski, R. and Redpath S. (2010). Economic values of species management options in human-wildlife conflicts: Hen harriers in Scotland. Ecological Economics, 70: 107-113 
Hensher, D., Rose, J. and Greene, W. (2005a). Applied choice analysis: A primer. Cambridge University Press, UK.

Hensher, D., Rose, J. and Greene, W. (2005b). The Implications on Willingness to Pay of Respondents Ignoring Specific Attributes, Transportation, 32: 203-222.

Johnston, R.J. and Duke, J. (2010). Socioeconomic adjustments and choice experiment benefit function transfer: Evaluating the common wisdom. Resource and Energy Economics, 32: 521-438.

Johnston, R.J. and Rosenberger, R.S. (2010). Methods, Trends and Controversies in Contemporary Benefit Transfer, Journal of Economic Surveys, 24(3): 479-510.

Johnston, R.J., Segerson, K., Schultz, E., Besedin, E. and Ramachandran, M. (2011). Indices of biotic integrity in stated preference valuation of aquatic ecosystem services. Ecological Economics, 70: 1946-1956.

Johnston, R., Schultz, E., Segerson, K., Besedin, E. and Ramachandran, M. (2013). Stated preferences for intermediate versus final ecosystem services: Disentangling willingness to pay for omitted outcomes. Agricultural and Resource Economics Review, 42(1): 98-118.

Kaul, S., Boyle, K.J., Kuminoff, N.V., Parmeter, C.F. and Pope, J.C. (2013). What Can we Learn from Benefit Transfer Errors? Evidence from 20 Years of Research on Convergent Validity, Journal of Environmental Economics and Management, 66: 90-104.

Kehlbacher, A., Balcombe, K. and Bennett, R. (2013). Stated Attribute Non-Attendance in Successive Choice Experiments, Journal of Agricultural Economics, 64(3): 693-706.

Kemp, P.S. and O'Hanley, J.R. (2010). Procedures for evaluating and prioritising the removal of fish passage barriers: A synthesis. Fisheries Management and Ecology, 17: 297 - 322.

King, S. and O'Hanley, J. R. (2016). Optimal Fish passage barrier removal - Revisited. River Research and Applications, DOI: 10.1002/rra.2859. 
Kragt, M.E. (2013). Stated and Inferred Attribute Attendance Models: A Comparison with Environmental Choice Experiments, Journal of Agricultural Economics, 64: 719-736.

Krinsky, I. and Robb, A. (1986). On Approximating the Statistical Properties of Elasticities, Review of Economics and Statistics, 68: 715-719.

Laitila, T. and Paulrud, A. (2008). Anglers' valuation of water regulation dam removal for the restoration of angling conditions at Storsjo-Kapell. Tourism Economics, 14(2): 283-296.

MacDonald, D., Morrison, M., Rose, J. and Boyle, K. (2011). Valuing a multistate river: The case of the River Murray. Australian Journal of Agricultural and Resource Economics, 55: 374-392.

Mariel, P., Meyerhoff, J. and Hess, S. (2013). Using a latent variable choice model to capture heterogeneous attitudes and preferences toward the landscape externalities of wind power generation. Renewable and Sustainable Energy Reviews, 41: 647-657.

Moghraby, C. (2008). Impact assessment of measures to address obstructions to the free passage of migratory and freshwater fish. Annex B, Consultation on Modernisation of Salmon and Freshwater Fisheries Legislation; New Order to Address the Passage of Fish. Department for Environment, Food and Rural Affairs, UK.

Morrison, M., Bennett, J., Blamey, R. and Louviere, J. (2002). Choice modeling and tests of benefit transfer. American Journal of Agricultural Economics, 84(1): 161-170.

Morrison, M. and Bennett, J. (2004). Valuing New South Wales rivers for use in benefits transfer. Australian Journal of Agricultural and Resource Economics, 48(4): 591-611.

Nilsson, C., Reidy, C.A., Dynesius, M. and Revenga, C. (2005). Fragmentation and flow regulation of the world's large river systems. Science, 308(5720): 405-408.

Nislow, K. H., Hudy, M., Letcher, B. H. and Smith, E. P. (2011). Variation in local abundance and species richness of stream fishes in relation to dispersal barriers: implications for management and conservation. Freshwater Biology, 56(10): 2135-2144. 
O’Hanley, J.R. (2011). Open Rivers: Barrier Removal Planning and the Restoration of FreeFlowing Rivers. Journal of Environmental Management, 92: 3112-3120.

O’Hanley, J. R., Wright, J., Diebel, M., Fedora, M. and Soucy, C. (2013). Restoring stream habitat connectivity: A proposed method for prioritizing the removal of resident fish passage barriers. Journal of Environmental Management, 125: 19-27.

Östberg, K., Håkansson, C., Hasselström, L. and Bostedt, G. (2013). Benefit Transfer for Environmental Improvements in Coastal Areas: General vs. Specific Models. Canadian Journal of Agricultural Economics, 62(2): 239-258.

Poe, G.L., Giraud, K.L. and Loomis, J.B. (2005). Computational Methods for Measuring the Difference of Empirical Distributions. American Journal of Agricultural Economics, 87(2): $353-365$

Rolfe, J., Bennett, J. and Louviere, J. (2002). Stated values and reminders of substitute goods: Testing for framing effects with choice modelling. Australian Journal of Agricultural and Resource Economics, 46(1): 1-20.

Rolfe, J. and Windle, J. (2012). Testing Benefit Transfer of Reef Protection Values Between Local Case Studies: The Great Barrier Reef in Australia, Ecological Economics, 81: 60-69.

Roni, P., Hanson, K., and Beechie, T. (2008). Global review of the physical and biological effectiveness of stream habitat rehabilitation techniques. North American Journal of Fisheries Management, 28: 856-890.

Scarpa, R., Zanoli, R., Bruschi, V. and Naspetti, S. (2013). Inferred and Stated Attribute NonAttendance in Food Choice Experiments, American Journal of Agricultural Economics, 95(1): 165-180.

Train, K. (2003). Discrete Choice Methods with Simulation. New York: Cambridge University Press. 
UK National Ecosystem Assessment (2011) Freshwaters - openwaters, wetlands and floodplains. Chapter 9, pp. 301. Available online: http://uknea.unepwcmc.org/Resources/tabid/82/Default.aspx <Accessed 08/12/2015>. 